\title{
Some problems in the assessment of handedness: Comment on Coren (1993)
}

\author{
RUSSELL EISENMAN \\ McNeese State University, Lake Charles, Louisiana
}

\begin{abstract}
The development by Coren (1993) of the Lateral Preference Inventory is an important advance for research on handedness, footedness, eyedness, and earedness. However, there are some problems in the assessment of handedness. Left-handed people live in a right-handed world and thus are deviant, relative to the majority. According to deviance theory (Eisenman, 1991), left-handed people are subject to all kinds of socially induced problems. Thus, many left-handed people will be forced, in one way or another, to use the nonpreferred right hand for a variety of tasks. Asking what hand they use may make them appear to be right-handed. Other issues are discussed, including the fact that I consider myself left-handed, yet would score right-handed on three of the four Coren (1993) handedness items.
\end{abstract}

Coren (1993) reported on the development of his Lateral Preference Inventory, which measures handedness, footedness, eyedness, and earedness. He also gave extensive references to his findings, many of them based on the use of the Lateral Preference Inventory. While his inventory is an important instrument that will facilitate research on various sidedness matters, there is a major problem in assessing someone's handedness. Coren has four questions in his inventory to assess handedness. I wish to discuss some of the problems that will be faced with the use of his four questions or the use of other attempts to determine handedness.

\section{Left-Handers as Deviant}

The majority of people are right-handed. This means that left-handed people are different, and, as I have pointed out (Eisenman, 1991), anything that is different is subject to being labeled as "deviant" by society, with penalties then imposed on deviant people. When I entered the first grade in New York City in 1946, I was left-handed, but was forced by my teacher to write right-handed. Thus, I had poor handwriting throughout my school career, and to this day I write right-handed. Since teachers often judge essays by how they look (some actually grade on "appearance'), I was constantly punished for having poor handwriting. While it is no longer common for teachers to try to convert all left-handed students to being righthanded (at least for writing), I have heard occasional stories about it still being done.

A left-handed person often faces objects or machinery made for right-handers and may have to learn to use some of these with the right hand. For example, all the desks in the rooms in which I teach are made for right-handed people. You enter the seat from the left, and the writing

Requests for reprints should be addressed to R. Eisenman, Department of Psychology, McNeese State University, Lake Charles, LA 70609-1895. top is on the right side. Or, when I try to open the container under the hood of my car to check my oil, it is almost impossible to turn it using my preferred left hand, since other things are built where the left hand would be placed. It is necessary for me to use my right hand to open the container.

\section{Score on the Lateral Preference Inventory}

My score on Coren's (1993) Lateral Preference Inventory for the four handedness items is 3 for being righthanded and 1 for being left-handed. Yet, by far, my strength and preference are left-handed. But, having been forced to learn to write as a right-hander, I answer Item 1 that I draw with my right hand, and Item 3 that I erase with my right hand. I suspect there is a high correlation between these items, and they may not be giving independent information. Also, on Item 4 ("which hand would I use to remove the top card from a deck"), my answer would be the right hand. I suspect that left-handed people often use their nonpreferred hand much more often than do right-handed people, in large measure because so many things in the world are set up to be dealt with via the right hand. The only item that reflects what I consider to be my true handedness is Item 2 , about throwing a ball, which I definitely do with my left hand.

I have much strength in my left hand and did well in such sports as boxing and baseball as a youth. My right hand is not noticeably strong. However, on Coren's (1993) inventory, I come out as a right-handed person on three of the four handedness items. If this misleading result would occur for many others, as I suspect it might, misleading data is being generated.

\section{Another Example}

Another example concerns my younger brother, who also plays sports as a left-hander, with one important exception. As a child, he admired Pee Wee Reese, a shortstop with the Brooklyn Dodgers. My brother imitated Pee 
Wee's batting style, which was that of a right-hander. So, my brother was a right-handed batter, although he threw left-handed. The concept of modeling seems relevant here. He modeled his hitting after his idol, and since, statistically, there are many more right-handed batters than lefthanded batters, he was likely to choose a right-hander to imitate.

\section{Final Thoughts on the Coren Inventory and Possible Improvements}

Coren (1993) reports a concordance of $92 \%$ between self-report on the Lateral Preference Inventory and direct behavioral performance on these items. But this does not take into account that his four-item handedness index may be misleading. He would probably get $100 \%$ concordance if he observed me doing the four things he includes in his index. But I still maintain that it is misleading to classify me as right-handed, or even as predominantly righthanded. His four-item index leaves out many factors. After all, four items are only four items, which is a very small sample of behavior. Perhaps future research could ask people to name their preferred hand and then try to see what might account for any discrepancy between what people say and what handedness they are assigned to on the basis of Coren's inventory or on the basis of some other assessment of handedness.

I understand that left-handers may be incorrectly classified. It might be that there are similar problems with right-handers. Perhaps people often do not fall into neat categories of being either right-handed or left-handed.

\section{REFERENCES}

CoRen, S. (1993). The lateral preference inventory for the measurement of handedness, footedness, eyedness, and earedness: Norms for young adults. Bulletin of the Psychonomic Society, 31, 1-3.

EISENMAN, R. (1991). From crime to creativity: Psychological and social factors in deviance. Dubuque, IA: Kendall/Hunt.

(Manuscript received February 11, 1993.) 